\title{
Origin of Meteoric Fluids in Extensional Detachments
}

\author{
Paul D. Bons $\mathbb{D}^{1,2}$ and Enrique Gomez-Rivas $\mathbb{D}^{3}$ \\ ${ }^{1}$ China University of Geosciences (Beijing), Xueyuan Road 29, Haidian District, 100083 Beijing, China \\ ${ }^{2}$ Department of Geosciences, Eberhard Karls University Tübingen, Tübingen 72074, Germany \\ ${ }^{3}$ Departament de Mineralogia, Petrologia i Geologia Aplicada, Universitat de Barcelona, Barcelona 08028, Spain
}

Correspondence should be addressed to Paul D. Bons; paul.bons@uni-tuebingen.de

Received 30 October 2019; Revised 9 January 2020; Accepted 13 January 2020; Published 6 February 2020

Academic Editor: Nicoló Colombani

Copyright (c) 2020 Paul D. Bons and Enrique Gomez-Rivas. This is an open access article distributed under the Creative Commons Attribution License, which permits unrestricted use, distribution, and reproduction in any medium, provided the original work is properly cited.

\begin{abstract}
Minerals in veins and shear zones often show oxygen and hydrogen isotope ratios that are interpreted as recording interaction with meteoric water, at depths up to about $10 \mathrm{~km}$. Downward fluid flow to these depths can only occur in the unlikely case of fluid pressures that are significantly lower than lithostatic overburden pressures. We therefore propose that fluid movement was upward instead of downward. In our model, the pore space within sediments and exhumed rocks below an unconformity is filled with meteoric and possibly seawater fluids. Burial of these rocks traps the fluids that can retain their meteoric isotopic composition as long as temperatures remain below about $300-350^{\circ} \mathrm{C}$. Extension or rapid exhumation, such as that experienced by metamorphic core complexes, which results in decompression or fluid heating can release these old "meteoric" fluids, of which we find the isotopic fingerprint in veins and shear zone minerals.
\end{abstract}

\section{Introduction}

Fluids of different origins are characterised by their typical chemical and isotopic composition [1]. Meteoric fluids, for example, are characterised by very low salinity and (relatively) low $\delta^{18} \mathrm{O}$ and $\delta \mathrm{D}$ values. Fluid composition and isotope ratios can change by a variety of processes, such as fluid-rock interaction, mixing with other fluids, and gravitational fractionation [2-7]. Unfortunately, it is usually difficult to directly measure the isotopic composition of palaeofluids. Instead, minerals that precipitated from or interacted with these fluids can be used to infer their compositions, as these fluids may have left their "fingerprint" or "signature" in the isotopic composition of the minerals (e.g., [7]). If the mineral data indicate that the fluid had the composition of a meteoric fluid, the mineral can be said to carry a "meteoric signature." The same applies to seawater, metamorphic, or magmatic signatures, among others. Similarly, a fluid has a "meteoric signature" if its composition is similar to that of meteoric water or of meteoric water that has been altered by, for example, fluid-rock interaction or mixing with other fluids (e.g., brines, metamorphic, and mag- matic). The term "signature" is used here to emphasise that whether or not a palaeofluid is meteoric, or has a meteoric component or origin, is an interpretation of compositional data, normally including isotopes, and not a direct observation in case of data derived from the mineral record.

Meteoric signatures, mostly $\delta^{18} \mathrm{O}$ values, have been claimed to be visible in veins and shear zones that formed in deep, even ductile parts of the crust [8-28]. For want of other explanations for these meteoric signatures, they are usually explained as resulting from interaction with meteoric water. This raises the question of how these surface waters reached the ductile parts of the crust with temperatures $\geq 300^{\circ} \mathrm{C}$ and depths over $10 \mathrm{~km}[11,22,23]$. Meteoric signatures are in particular found in mylonitic detachment zones of metamorphic core complexes, which are formed during rapid exhumation $[13-16,20,21,29]$. The meteoric signature in these studies is constituted by (i) lowered $\delta^{18} \mathrm{O}$ values in the detachment, relative to the adjacent less-deformed rocks, (ii) low (mostly $<-100 \%$ o $\delta \mathrm{D}$ values in micas, especially inside the detachment, and (3) low $\delta \mathrm{D}$ values in fluid inclusions in quartz. To explain these observations, most current authors favour downward flow of meteoric fluid along extensional faults or 
detachments in association with exhumation and shearing of the rocks in which the meteoric signature is found (e.g., $[9,20$, $21,30-32])$, even to depths of up to $20 \mathrm{~km}[17,22]$. The alternative model of Clark et al. [12] envisages that the rocks achieved their meteoric signature at near-surface conditions and were subsequently buried. The meteoric signature observed in the detachment would then be inherited and not the result of deep penetration of meteoric fluids. However, the observed isotopic shifts that authors such as Mulch et al. [21] and Gébelin et al. [29] use to infer a meteoric fluid influx into metamorphic core complex detachments are more prominent in the top of the detachments, where shearing is most intense, compared to footwall rocks further down. This would suggest that the rocks did not carry an inherited meteoric signature before the detachment activity but that the isotopic shifts occurred during shearing.

A problem with the downward flow of fluid is that deep circulation of fluids is only possible when the fluid pressure is near hydrostatic $[9,12]$. Only then can fluids penetrate deeply due to topography differences or thermally induced convection, as envisioned by the aforementioned authors. Circulation of fluids from the surface to a depth of up to even $20 \mathrm{~km}$ and temperatures of around $400^{\circ} \mathrm{C}$ has indeed been modelled numerically (e.g., [17, 22, 23, 33]). To achieve such circulation and maintain it over hundreds of thousands of years or more, these authors used constant and high permeabilities of $10^{-15}$ to $10^{-14} \mathrm{~m}^{2}$ and typically high porosities of up to $10 \%$ [33] for the fault zones. Note that these permeabilities are high and expected for upper crustal rocks $(<5 \mathrm{~km}$ depth; [34]) with high intergranular porosities (ca. 10\%) or alternatively (micro-)fracturing or damage zones [35-37]. Furthermore, a hydrostatic fluid pressure at 10 to $20 \mathrm{~km}$ depth implies that the difference between fluid and lithostatic pressure is about 1.7 to $3.4 \mathrm{kbar}$, unless there is a seal higher up in the system. As already pointed out by Bons et al. [38], it is highly unlikely that such a fluid underpressure can be maintained under ductile conditions at elevated temperatures.

The intense shear fabrics (mylonitic fabric, recrystallised quartz, and mica fish) of the mylonitic rocks of detachments in which evidence for meteoric fluids was found (e.g., the Columbia River Fault; [23]; or the South Tibet Detachment; [15]) are evidence of the ability of these rocks to flow ductilely. The difference in fluid and solid pressure would drive ductile flow of the rock around pores and fractures to equalise the pressure. Here, we present a simple numerical model to demonstrate that less than a million years are required to equalise $50 \%$ the fluid and solid pressure in a rock's pore at a temperature above about 250 to $400^{\circ} \mathrm{C}$, assuming a spherical pore surrounded by ductile quartz rock that flows in to equalise the pressure difference (see Methods and Results and Discussion for details). Note that (i) at $50 \%$ pressure equilibration, fluid pressure is significantly above hydrostatic pressure and hydraulic head gradients will drive fluid upward and (ii) this temperature range corresponds to the brittle-toductile transition (e.g., [39] and references therein).

Because of the arguments given above, it is highly unlikely, if not impossible, to drive meteoric fluids down to ductile regimes where the temperature is in the order of 300 to $400^{\circ} \mathrm{C}$ for any prolonged period of time. This implies that the faults and shear zones that now exhibit the meteoric water signature were not themselves involved in the downward transport of the meteoric water and that the downward transport did not occur at the same time of the recording of the meteoric signature in the rocks. Raimondo et al. [27] suggested that the fault rocks acquired their meteoric signature near the surface (where meteoric fluid flow and alterations are not controversial) and were then buried and later reactivated as midcrustal shear zones. As an alternative, we argue that the meteoric fluids were originally near-surface pore waters that were buried passively [40]. By using an oxygen isotope diffusion model, we show how such old meteoric fluids were able to keep their isotopic signatures for long time (tens to hundreds of million years) if their temperature was below about $350^{\circ} \mathrm{C}$. We also discuss mechanisms for the upward release of such trapped fluids during exhumation and present fluid budgets for an idealised metamorphic core complex. The model we present here, in which fluid infiltration and release are separated in time, is a hydrodynamically feasible alternative to the classical paradigm in which downward flow and upward flow are simultaneous.

\section{Methods}

2.1. Model to Calculate the Rate of Fluid and Rock Pressure Equilibration. To constrain the time it would take to equalise the fluid and solid pressure, we here consider the idealised case of a perfect fluid-filled sphere surrounded by solid, ductile rock that flows in to equalise the pressure difference. A sphere is the most robust structure, and any other geometry of a pore would close faster than a sphere. Assuming, for simplicity, that the rock is an incompressible material with a rheology that can be represented by the quartz flow laws of Paterson and Luan [41] or Gleason and Tullis [42], we can employ the equations by Nye [43], derived again by Dabrowski et al. [44], to calculate the rate of pressure equilibration between fluid and rock. Or, in other words, we can estimate what the shrinking rate of a fluid-filled inclusion is.

Nye [43] derived the equations for the shrinking of an underpressured spherical inclusion for the case that is controlled by the rheology of the embedding matrix. The matrix is assumed to be an incompressible material with a power-law rheology that relates the strain intensity $(\dot{\varepsilon})$ to the stress $(\tau)$ :

$$
\dot{\varepsilon}=\left(\frac{\tau}{B}\right)^{n}
$$

Here, $n$ is the stress exponent and $B$ is a rate constant. Note that flow laws for rock-forming minerals are usually expressed in a different way with instead a rate constant $A$. The conversion will be discussed below. Strain intensity and stress are derived from the strain rate $(\dot{E})$ and the deviatoric stress tensor $(\Sigma)$ :

$$
\begin{aligned}
& 2 \dot{\varepsilon}^{2}=\dot{E}_{i j} \dot{E}_{i j}, \\
& 2 \tau^{2}=\Sigma_{i j} \Sigma_{\mathrm{i} j} .
\end{aligned}
$$


For an isolated spherical inclusion with radius $a$, the radial stress $\left(\sigma_{\mathrm{r}}\right)$ is now given by

$$
\frac{\sigma_{\mathrm{r}}}{\sigma_{a}}=\left(\frac{a}{r}\right)^{3 / n}
$$

where $\sigma_{a}$ is the stress at the surface of the inclusion, at distance $r=a$, assuming zero radial stress at infinity. $\sigma_{a}$ thus equals the pressure difference, $\Delta P$, between solid and fluid in the inclusion. The rate of contraction is

$$
\frac{1}{a} \frac{d a}{d t}=3^{(1 / 2)(n-1)}\left(\frac{\Delta P}{2 n B}\right)^{n} \Leftrightarrow \frac{1}{V} \frac{d V}{d t}=3^{(1 / 2)(n+1)}\left(\frac{\Delta P}{2 n B}\right)^{n}
$$

Flow laws for rock-forming minerals, such as quartz, are typically derived from uniaxial shortening experiments and reported as

$$
\dot{\varepsilon}_{z}=A \sigma_{z}^{n}, \quad A=A_{0} \exp ^{-Q / R T} .
$$

The subscript $z$ refers to the direction of uniaxial shortening, $A_{0}$ is the preexponential rate factor, $Q$ is the activation energy, $R$ is the universal gas constant, and $T$ is the absolute temperature. To obtain the rate factor $B$ that is used above, we use $\tau=\sqrt{2 / 3} \sigma_{z}$ and $\dot{\varepsilon}=\sqrt{2} \dot{\varepsilon}_{z}$ to obtain

$$
\frac{\dot{\varepsilon}}{\sqrt{2}}=A\left(\frac{\tau}{\sqrt{2 / 3}}\right)^{n} \Leftrightarrow B=\sqrt{\frac{2}{3}}(\sqrt{2} A)^{-1 / n} .
$$

To calculate the shrinkage rate of an inclusion, one needs to take into account the change in pressure within the inclusion. We use a compressibility of $K=2 \mathrm{GPa}$, with

$$
\begin{aligned}
\frac{V}{V_{0}} & =\exp ^{-\Delta P / K} \Leftrightarrow \Delta P=-K \ln \left(\frac{V}{V_{0}}\right) \\
& =-K \ln V-K \ln V_{0} \Leftrightarrow \frac{d \Delta P}{d V}=-\frac{K}{V} .
\end{aligned}
$$

Here, $V_{0}$ is the reference volume at which $\Delta P=0$. The change in pressure difference between the fluid and the matrix can now be related to the matrix rheology:

$$
\begin{aligned}
\frac{d \Delta P}{d t} & =\frac{d \Delta P}{d V} \frac{d V}{d t}=-\frac{K}{V} \frac{d V}{d t}=-K 3^{(1 / 2)(n+1)}\left(\frac{\Delta P}{2 n B}\right)^{n} \\
& =-K 3^{(1 / 2)(n+1)}(2 n B)^{-n} \Delta P^{n} \Leftrightarrow \frac{d \Delta P}{P^{n}} \\
& =-K 3^{(1 / 2)(n+1)}(2 n B)^{-n} d t \Leftrightarrow(\Delta P)^{1-n} \\
& =-K(1-n) 3^{(1 / 2)(n+1)}(2 n B)^{-n} t+c .
\end{aligned}
$$

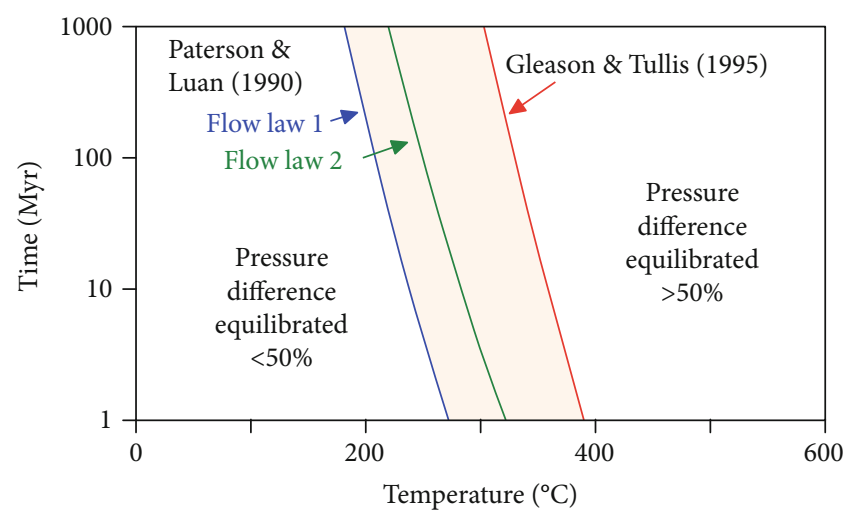

FIgURE 1: Time for a spherical fluid-filled inclusion to reach $50 \%$ pressure equilibration, starting with a hydrostatic pressure (assuming $\rho_{\text {fluid }}=1000 \mathrm{~kg} / \mathrm{m}^{3}$ ) in a quartz matrix at lithostatic pressure (assuming $\rho_{\text {matrix }}=2750 \mathrm{~kg} / \mathrm{m}^{3}$ ). The geotherm is set at $30^{\circ} \mathrm{C} / \mathrm{km}$ at a surface temperature of $15^{\circ} \mathrm{C}$. Flow laws used are from Paterson and Luan [41] and Gleason and Tullis [42] (see Table 1).

TABle 1: Parameters of the quartz flow law used in this study.

\begin{tabular}{lccc}
\hline Source & $n$ & $A_{0}\left(\mathrm{MPa}^{-n} / \mathrm{s}\right)$ & $\begin{array}{c}\mathrm{Q} \\
(\mathrm{kJ} / \mathrm{mol})\end{array}$ \\
\hline Gleason and Tullis [42] & 4 & $1.1 \cdot 10^{-4}$ & 223 \\
Paterson and Luan [41]; flow law 1 & 3.1 & $6.5 \cdot 10^{-8}$ & 135 \\
Paterson and Luan [41]; flow law 2 & 4 & $4.0 \cdot 10^{-10}$ & 135 \\
\hline
\end{tabular}

The integration constant $c$ equals $\left(\Delta P_{0}\right)^{1-n}$, with $\Delta P_{0}$ the initial pressure difference at $t=0$. From this, we finally derive the time, $t(\Delta P)$, needed to achieve a pressure difference $\Delta P$ :

$$
t(\Delta P)=\frac{\left(\Delta P_{0}\right)^{1-n}-(\Delta P)^{1-n}}{K(1-n) 3^{(1 / 2)(n+1)}(2 n B)^{-n}} .
$$

\section{Results and Discussion}

3.1. Fluid and Rock Pressure Equilibration at the Brittle-toDuctile Transition. We present models based on the method presented above to estimate the rate of equilibration of a fluid-filled spherical pore within a ductile quartz rock to show that the time to equilibrate the pressure difference between a fluid at hydrostatic pressure and the solid matrix at lithostatic pressure by $50 \%$ depends strongly on the temperature and, hence, on depth (Figure 1). Using the three flow laws proposed by Paterson and Luan [41] or Gleason and Tullis [42] (see Table 1), we see that this time quickly reduces from many millions of years to less than a million year in the temperature range somewhere between about 250 and $400^{\circ} \mathrm{C}$, which coincides with the brittle-ductile transition condition. Note that at $50 \%$ pressure equilibration, fluid pressure is significantly above hydrostatic pressure and hydraulic head gradients will drive fluid upward. This clearly demonstrates that it is nearly impossible to drive meteoric fluids down to crustal zones where ductile deformation dominates (and where temperatures are on the order of 
250 to $400^{\circ} \mathrm{C}$ ) for prolonged periods of time. Therefore, downward and upward flow of meteoric fluids could not take place simultaneously along extensional faults, and an alternative model in which meteoric fluid infiltration and release are separated in time is required.

3.2. Origin and Burial of Meteoric Fluid. The German KTB drill hole shows that meteoric fluid can penetrate deep below the erosion surface. Fluid pressure is hydrostatic down to $9 \mathrm{~km}$ where the temperature is about $275^{\circ} \mathrm{C}$ [45]. The close to hydrostatic pressure at this depth and temperature is consistent with the results shown in Figure 1, where time to pressure equilibration starts to reduce significantly just above this temperature, except when using the "softest" flow law of Paterson and Luan [41]. Porosities are about $1 \%$, with local excursions up to $\geq 5 \%$ in fault zones, at least down to $4 \mathrm{~km}$ depth. Below $4 \mathrm{~km}$, the porosity decreases somewhat [45], possibly down to about $0.1 \%$ [46]. With a geothermal gradient of $28^{\circ} \mathrm{C} / \mathrm{km}$, the decline in porosity in the KTB drill hole occurs at about $110^{\circ} \mathrm{C}$. The depth of fluid infiltration is probably strongly temperature-dependent (see above). Infiltration may therefore be double the depth in old cratonic basement rocks with a low geothermal gradient. Below an unconformity, one can thus expect several kilometres of thick zone permeated by a significant amount of meteoric water $[3,40]$. Renewed sedimentation will bury the infiltrated zone, together with its pore fluid. Burial may be enhanced by an orogenic event, with the emplacement of nappes on top of the unconformity. Pore fluid will become trapped during burial as pore space becomes disconnected and close. At the end of burial, a package of rock with a more or less pressure-equilibrated meteoric fluid is brought down to deeper crustal levels.

3.3. Preserving the Meteoric Isotope Ratios in a Pore Fluid. A crucial question to address now is how long the meteoric isotope signature of the pore fluid can be preserved. Since the postulated deep infiltration of meteoric fluids is mostly based on $\delta^{18} \mathrm{O}$ values, we only consider these here.

We first consider oxygen and quartz, which is one of the most abundant crustal minerals. For a rock volume at rest, we assume that the isotopic equilibration is controlled by diffusion of the isotope in the minerals that surround the pores. A pore of size $s$ must exchange isotopes with the surrounding mineral in a zone with a width in the same order of $s$. A pore is thus approximately isotopically equilibrated in a time $(t)$ that is needed to diffuse the mean distance $s$, given by $s^{2}=$ $D \cdot t$, where $D$ is the diffusion coefficient. Using the preexponential constant $\left(D_{0}=2.9 \cdot 10^{-5} \mathrm{~m}^{2} / \mathrm{s}\right)$ and activation energy $(243 \mathrm{~kJ} / \mathrm{mol})$ of Farver and Yund [47], we see that it takes many millions of years to diffuse $>1 \mu \mathrm{m}$ when the temperature is below about $300^{\circ} \mathrm{C}$ (Figure 2).

This simple approximation of the isotopic equilibrium time for fluid in rocks shows that fluids can retain their oxygen-isotopic signature for long periods of time (millions of years) below the brittle-ductile transition at about 300$350^{\circ} \mathrm{C}$, which is also the temperature range where dynamic recrystallisation sets in. This, however, only applies when the rocks remained at rest. Deformation, such as cataclasis,

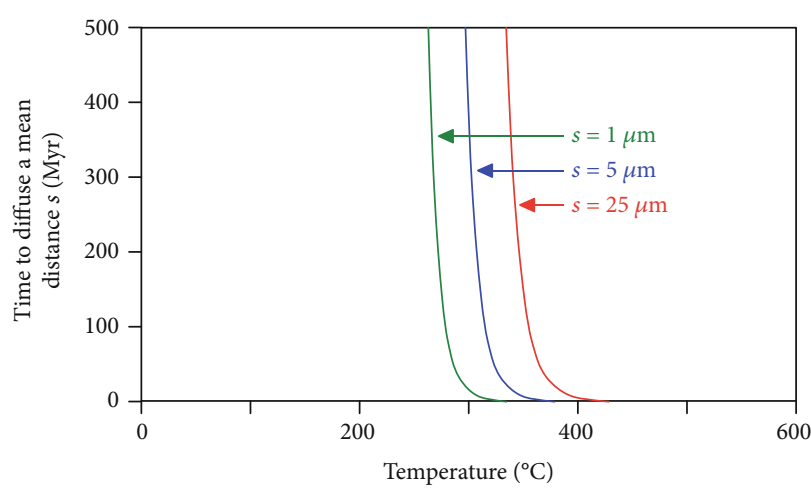

Figure 2: Time ( $t$ in Myr) to diffuse oxygen a distance $s$ of 5, 10, and $20 \mu \mathrm{m}$ in quartz as a function of temperature based on diffusion data of Farver and Yund [47].

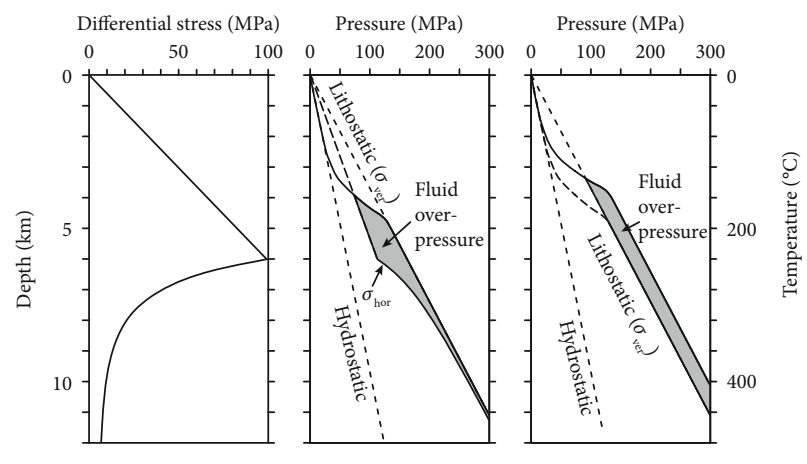

FIGURE 3: Schematic differential stress and pressure profiles. (a) Absolute differential stress to achieve an extension rate that is depth-independent, assuming a maximum differential stress of $100 \mathrm{MPa}$ at a brittle-ductile transition of about $6 \mathrm{~km}$. (b) In a crust at rest, the fluid pressure profile would show a transition from hydrostatic at a shallow depth to lithostatic further down. Grey area shows the fluid overpressure that results from bringing the crust under extension. (c) Exhumation shifts the fluid pressure profile upward if fluid cannot escape from the pores. Grey area shows the resulting fluid overpressure. Both extension and exhumation may thus result in fluid pressures that exceed the lithostatic and thereby cause fluid release.

would enhance isotopic exchange and equilibration at lower temperatures (as envisaged by [27]). This process only affects a small portion of the total rock volume, allowing most of the fluid to keep their original signature at low temperatures. Compaction of a rock by pressure solution $[48,49]$ involves dissolution of solid and its reprecipitation. This would lead to a quick equilibration of isotopes in the pore fluid and the solid. Whereas this is likely in the case of initially highporosity sediments, metamorphic or igneous basement rocks do not compact, as their initial porosity is already low. It should further be noted that the equilibrium rates used here are several orders of magnitude slower than those reported in Person et al. [23]. The difference is caused by these authors using a reaction-controlled equilibrium rate, which does not apply if the rock is at rest and the exchange of isotopes is controlled by the solid-state diffusion towards the fluid-mineral interface. Once rocks reach the ductile regime, dynamic 


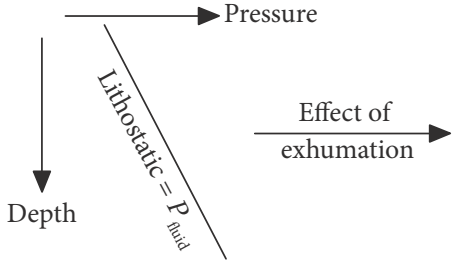

(a)

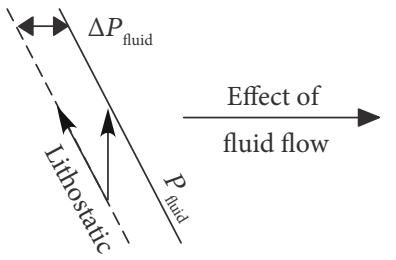

(b)

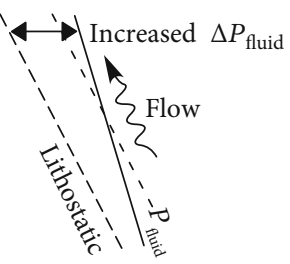

(c)

FIgURE 4: Fluid overpressure resulting from exhumation and fluid flow. (a) Initial situation where fluid pressure equals lithostatic pressure. (b) For a given rock volume, exhumation results in an upward shift along the lithostatic pressure gradient. Trapped pore fluid maintains its pore pressure and becomes overpressured. (c) Fluid flow will lead to a decrease of the fluid pressure gradient, increasing the overpressure downstream.

recrystallisation, including grain boundary migration, can greatly enhance fluid-rock interaction.

The same rationale can be applied to hydrogen isotopic ratios. A difference with oxygen, however, is that hydrogen is much less abundant in rocks than oxygen. About $8 \%$ of all hydrogen atoms reside in the pore fluid in the case of a pure biotite or muscovite schist with $1 \%$ porosity. In most cases, therefore, the hydrogen reservoir in the pore fluid is of the same order of magnitude as that of the rock, and the hydrogen isotopic ratio of a stagnant pore fluid will never be completely overprinted by that of the rock.

3.4. Exhumation and Release of Fluids. A characteristic of shear zones and faults with a meteoric signature is that they formed during (rapid) exhumation. The detachment faults of core complexes are prime examples (e.g., [23]). Exhumation can lead to the release of pore fluids, due to the difference in compressibility of fluid and rock [50]. Upon exhumation, the lithostatic pressure in a rock volume is reduced instantaneously. Fluid pressure does not immediately record this decompression, as the fluid-filled pores adjust their volume more slowly. A decrease in effective lithostatic pressure can also be induced by an extensional stress field, as the effective pressure is the average of the overburden and horizontal stresses. Fluid originally in pressure equilibrium with their host will thus become overpressured during exhumation, especially during extension (Figure 3 ).

The effect of overpressure on fluid-filled pores is not simply the inverse of that of underpressure. Whereas closing an underpressured pore during burial is a stable process, the opening of an overpressured pore to equilibrate solid and fluid pressure is unstable, because rocks cannot sustain significant fluid overpressure [51]. Overpressure is likely to result in (intergranular) cracks that rapidly create a permeability through which the overpressured fluid can flow upward. This leads to interaction with other overpressured pores and the possibility of a runaway effect $[52,53]$. This runaway effect would be enhanced if the newly created permeability allows the fluid pressure gradient to decrease towards hydrostatic. This reduces the fluid pressure upstream but increases it downstream (at a shallower depth). This effect leads to the upward propagation of hydrofractures (Figure 4) [54].

Summarising, extension and exhumation lead to relative overpressure in any fluid that is trapped in porosity and has

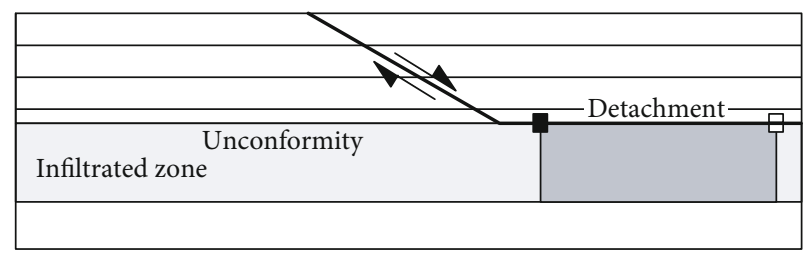

(a)

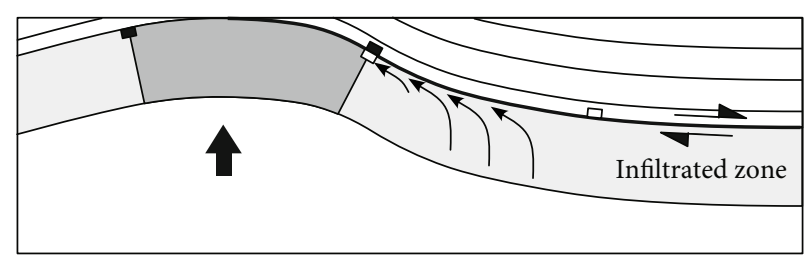

(b)

FIgURE 5: (a) Initial geometry of a buried unconformity with an infiltration zone in which the pores are filled by surface water (grey zone). A normal fault with detachment nucleates on this unconformity. (b) A core complex has formed. All rocks in the dark grey area have passed below the black split marker. During extension and exhumation, this volume would have released fluid, which would have been focused into the detachment zone.

reached approximate pressure equilibrium with the lithostatic pressure when the crust was at rest. Overpressure leads to the creation of permeability, and part of the fluid will migrate upward, driven by the high hydraulic gradient.

3.5. Fluid Budgets. To gain an impression of the amount of meteoric fluid that could pass through a fault or shear zone, we consider a schematic core complex with one major detachment fault. The detachment is situated on the unconformity that separates fluid-impregnated basement rocks (the "infiltration zone") from a cover series (Figure 5(a)). Movement along the detachment and updoming produce a core complex with the exhumed basement reaching the surface (Figure 5(b)). The offset along the fault is visualised by two split markers just below and above the detachment, separated by the amount of offset on the detachment. The figure shows that a section as long as the offset on the fault of the basement passes each point along the fault. The section passing below the upper black marker is marked in darker grey.

The basement, being stretched and exhumed, releases trapped fluid, which will move upward towards the detachment. The hanging wall does not experience any increase in 
permeability, as it is moving horizontally or downward, which decreases its permeability. Flow is thus focused into the detachment fault. This way, the detachment experiences a high flux of fluids that came from deeper and hotter levels in the crust. Most fluid-rock exchange is expected at the detachment, as is observed in, for example, the Columbia River Detachment [21].

All the fluid released by the grey rectangle passes below the upper black marker in Figure 5. If the offset along the detachment is $15 \mathrm{~km}$ and the thickness of the infiltration zone is $5 \mathrm{~km}$, with a $1 \%$ porosity, the total available fluid budget is $75 \cdot 10^{6} \mathrm{~m}^{3}$ per $1 \mathrm{~m}$ width of the fault zone. Not all of this fluid needs to be liberated by the decompression resulting from extension, doming, and movement along the detachment. A conservative estimate would be about $4 \%$, which is equivalent to the fraction of fluid release needed to equilibrate fluid and rock pressure if the fluid is overpressured by $100 \mathrm{MPa}$ (equivalent to about $4 \mathrm{~km}$ exhumation, see [50]). If this $4 \%$ of the available fluid is released and focused in a $100 \mathrm{~m}$ wide shear zone, the integrated fluid flux is $3 \cdot 10^{4} \mathrm{~m}^{3} / \mathrm{m}^{2}$. At $5 \%$ porosity in the shear zone, and a duration of 200,000 years for the event [23], this is equivalent to a flow rate of $3 \mathrm{~m} / \mathrm{y}$. This qualitative example shows that significant fluid fluxes can be generated that are in the order of those postulated for the Columbia River Detachment [23], but with a radically different source of the meteoric fluids.

The integrated fluid flux is highest at the top of the shear zone, as deeper levels of the shear zone arrived at the reference point later. It is expected that any alteration of the shear zone increases towards the top of the shear zone and then decreases abruptly into the hanging wall, which is exactly as observed in the Columbia River Detachment [23].

\section{Conclusions}

Meteoric fluid signatures are often found in midcrustal shear zone minerals. This does not necessarily mean that these fluids infiltrated at the time that these shear zones were active, as is often assumed. Meteoric signatures can be preserved for long periods of time, as long as the temperature does not exceed about $300-350^{\circ} \mathrm{C}$ for oxygen in a quartz-dominated rock. This means that meteoric water can infiltrate down from an erosional surface to be buried and subsequently remobilised many million years later. The crucial point is that the meteoric signature found in shear zones is then from fluid flowing upward, not downward.

\section{Data Availability}

All the models and data in this article are based on the equations published here and parameters described in the main text and Table 1. The models can be reproduced with standard spreadsheet software.

\section{Conflicts of Interest}

The authors declare that there is no conflict of interest regarding the publication of this paper.

\section{Acknowledgments}

This study was developed within the framework of DGMK (German Society for Petroleum and Coal Science and Technology) project 718, funded by the companies ExxonMobil Production Deutschland GmbH, GDF SUEZ E\&P Deutschland GmbH, RWE Dea AG, and Wintershall Holding $\mathrm{GmbH}$. EGR acknowledges funding by the AGAUR (Agència de Gestió d'Ajuts Universitaris i de Recerca) of the Generalitat de Catalunya ("Beatriu de Pinós" fellowship 2017SGR-824) and the Spanish Ministry of Science, Innovation and Universities ("Ramón y Cajal" fellowship RYC2018026335-I and research project PGC2018-093903-B-C22).

\section{References}

[1] S. M. F. Sheppard, "Characterization and isotopic variations in natural waters," Stable Isotopes in High Temperature Geological Processes, J. W. Valley, H. P. Taylor, and J. R. O’Neil, Eds., pp. 165-183, 1986.

[2] J. L. Banner and G. N. Hanson, "Calculation of simultaneous isotopic and trace element variations during water-rock interaction with applications to carbonate diagenesis," Geochimica et Cosmochimica Acta, vol. 54, no. 11, pp. 3123-3137, 1990.

[3] P. D. Bons and E. Gomez-Rivas, "Gravitational fractionation of isotopes and dissolved components as a first-order process in crustal fluids," Economic Geology, vol. 108, no. 5, pp. 1195-1201, 2013.

[4] P. I. Nabelek, "General equations for modeling fluid/rock interaction using trace elements and isotopes," Geochimica et Cosmochimica Acta, vol. 51, no. 6, pp. 1765-1769, 1987.

[5] G. Schwinn, T. Wagner, B. Baatartsogt, and G. Markl, “Quantification of mixing processes in ore-forming hydrothermal systems by combination of stable isotope and fluid inclusion analyses," Geochimica et Cosmochimica Acta, vol. 70, no. 4, pp. 965-982, 2006.

[6] Z. Sharp, Principles of Stable Isotope Geochemistry, University of New Mexico, 2nd Ed edition, 2017.

[7] J. W. Valley, H. P. Taylor, and J. R. O'Neil, "Stable isotopes in high temperature geological processes," Mineralogical Society of America, Reviews in Mineralogy, vol. 16, 1986.

[8] B. Baatartsogt, G. Schwinn, T. Wagner, H. Taubald, T. Beitter, and G. Markl, "Contrasting paleofluid systems in the continental basement: a fluid inclusion and stable isotope study of hydrothermal vein mineralization, Schwarzwald district, Germany," Geofluids, vol. 7, no. 2, 147 pages, 2007.

[9] A. J. Barker, D. G. Bennett, A. J. Boyce, and A. E. Fallick, "Retrogression by deep infiltration of meteoric fluids into thrust zones during late-orogenic rapid unroofing," Journal of Metamorphic Geology, vol. 18, no. 3, pp. 307-318., 2000.

[10] G. E. Bebout, D. J. Anastasio, and J. E. Holl, "Synorogenic crustal fluid infiltration in the Idaho-Montana thrust belt," Geophysical Research Letters, vol. 28, no. 22, pp. 4295-4298, 2001.

[11] I. Cartwright and I. S. Buick, "The flow of surface-derived fluids through Alice Springs age middle-crustal ductile shear zones, Reynolds Range, central Australia," Journal of Metamorphic Geology, vol. 17, no. 4, pp. 397-414, 1999.

[12] C. Clark, M. Hand, K. Faure, and A. S. Mumm, "Up-temperature flow of surface-derived fluids in the mid-crust: the role of 
pre-orogenic burial of hydrated fault rocks," Journal of Metamorphic Geology, vol. 24, no. 5, pp. 367-387, 2006.

[13] H. C. Fricke, S. M. Wickham, and J. R. O'Neil, "Oxygen and hydrogen isotope evidence for meteoric water infiltration during mylonitization and uplift in the Ruby Mountains-East Humboldt Range core complex, Nevada," Contributions to Mineralogy and Petrology, vol. 111, no. 2, pp. 203-221, 1992.

[14] A. Gébelin, C. Teyssier, M. T. Heizler, and A. Mulch, "Meteoric water circulation in a rolling-hinge detachment system (northern Snake Range core complex, Nevada)," Geological Society of America Bulletin, vol. 127, no. 1-2, pp. 149-161, 2015.

[15] A. Gébelin, M. J. Jessup, C. Teyssier et al., "Infiltration of meteoric water in the South Tibetan Detachment (Mount Everest, Himalaya): when and why?" Tectonics, vol. 36, no. 4, pp. 690-713, 2017.

[16] R. Gottardi, C. Teyssier, A. Mulch et al., "Strain and permeability gradients traced by stable isotope exchange in the Raft River detachment shear zone, Utah," Journal of Structural Geology, vol. 71, pp. 41-57, 2015.

[17] S. K. Matthäi, C. A. Heinrich, and T. Driesner, "Is the Mount Isa copper deposit the product of forced brine convection in the footwall of a major reverse fault?," Geology, vol. 32, no. 4, pp. 357-360, 2004.

[18] A. M. McCaig, "Deep fluid circulation in fault zones," Geology, vol. 16, no. 10, pp. 867-870, 1988.

[19] K. Methner, A. Mulch, C. Teyssier et al., "Eocene and Miocene extension, meteoric fluid infiltration and core complex formation in the Great Basin (Raft River Mountains, Utah)," Tectonics, vol. 34, no. 4, pp. 680-693, 2015.

[20] J. Morrison, "Meteoric water-rock interaction in the lower plate of the Whipple Mountain metamorphic core complex, California," Journal of Metamorphic Geology, vol. 12, no. 6, pp. 827-840, 1994.

[21] A. Mulch, C. Teyssier, M. A. Cosca, and C. P. Chamberlain, "Stable isotope paleoaltimetry of Eocene core complexes in the North American Cordillera," Tectonics, vol. 26, no. 4, 2007.

[22] N. H. S. Oliver, J. G. McLellan, B. E. Hobbs, J. S. Cleverley, A. Ord, and L. Feltrin, "100th Anniversary Special Paper: Numerical models of extensional deformation, heat transfer, and fluid flow across basement-cover interfaces during basinrelated mineralization," Economic Geology, vol. 101, no. 1, pp. 1-31, 2006.

[23] M. Person, A. Mulch, C. Teyssier, and Y. Gao, "Isotope transport and exchange within metamorphic core complexes," American Journal of Science, vol. 307, no. 3, pp. 555-589, 2007.

[24] A. Quilichini, L. Siebenaller, W. O. Nachlas et al., "Infiltration of meteoric fluids in an extensional detachment shear zone (Kettle dome, WA, USA): How quartz dynamic recrystallization relates to fluid- rock interaction," Journal of Structural Geology, vol. 71, pp. 71-85, 2015.

[25] A. Quilichini, L. Siebenaller, C. Teyssier, and T. W. Vennemann, "Magmatic and meteoric fluid flow in the Bitterroot extensional detachment shear zone (MT, USA) from ductile to brittle conditions," Journal of Geodynamics, vol. 101, pp. 109-128, 2016.

[26] T. Raimondo, C. Clark, M. Hand, and K. Faure, "Assessing the geochemical and tectonic impacts of fluid-rock interaction in mid-crustal shear zones: a case study from the intracontinental Alice Springs Orogen, Central Australia," Journal of Metamorphic Geology, vol. 29, no. 8, pp. 821-850, 2011.
[27] T. Raimondo, C. Clark, M. Hand, J. Cliff, and R. Anczkiewicz, "A simple mechanism for mid-crustal shear zones to record surface derived fluid signatures," Geology, vol. 41, no. 6, pp. 711-714, 2013.

[28] C. M. Read and I. Cartwright, "Meteoric fluid infiltration in the middle crust during shearing: examples from the Arunta Inlier, central Australia," Journal of Geochemical Exploration, vol. 69-70, pp. 333-337, 2000.

[29] A. Gébelin, A. Mulch, C. Teyssier, M. Heizler, T. Vennemann, and N. C. A. Seaton, "Oligo-Miocene extensional tectonics and fluid flow across the Northern Snake Range detachment system, Nevada," Tectonics, vol. 30, no. 5, 2011.

[30] S. Haines, E. Lynch, A. Mulch, J. W. Valley, and B. van der Pluijm, "Meteoric fluid infiltration in crustal-scale normal fault systems as indicated by $\delta 18 \mathrm{O}$ and $\delta 2 \mathrm{H}$ geochemistry and40Ar/39Ar dating of neoformed clays in brittle fault rocks," Lithosphere, vol. 8, no. 6, pp. 587-600, 2016.

[31] R. Hetzel, H. Zwingmann, A. Mulch et al., "Spatiotemporal evolution of brittle normal faulting and fluid infiltration in detachment fault systems: a case study from the Menderes Massif, western Turkey," Tectonics, vol. 32, no. 3, pp. 364376, 2013.

[32] L. Siebenaller, M. . C. Boiron, O. Vanderhaeghe et al., "Fluid record of rock exhumation across the brittle-ductile transition during formation of a Metamorphic Core Complex (Naxos Island, Cyclades, Greece)," Journal of Metamorphic Geology, vol. 31, no. 3, pp. 313-338, 2013.

[33] V. Harcouët-Menou, L. Guillou-Frottier, P. Bonneville, M. Adler, and V. Mourzenko, "Hydrothermal convection in and around mineralized fault zones: insights from two- and three-dimensional numerical modeling applied to the Ashanti belt, Ghana," Geofluids, vol. 9, no. 2, 137 pages, 2009.

[34] S. E. Ingebritsen and C. E. Manning, "Permeability of the continental crust: dynamic variations inferred from seismicity and metamorphism," Geofluids, vol. 10, 205 pages, 2010.

[35] Y. Bernabé, U. Mok, and B. Evans, "Permeability-porosity relationships in rocks subjected to various evolution processes," Pure and Applied Geophysics, vol. 160, no. 5, pp. 937960, 2003

[36] J. P. Evans, C. B. Forster, and J. V. Goddard, "Permeability of fault-related rocks, and implications for hydraulic structure of fault zones," Journal of Structural Geology, vol. 19, no. 11, pp. 1393-1404, 1997.

[37] Y. Yang and A. C. Aplin, "A permeability-porosity relationship for mudstones," Marine and Petroleum Geology, vol. 27, no. 8, pp. 1692-1697, 2010.

[38] P. D. Bons, M. A. Elburg, and E. Gomez-Rivas, "A review of the formation of tectonic veins and their microstructures," Journal of Structural Geology, vol. 43, pp. 33-62, 2012.

[39] J. M. Nevitt, J. M. Warren, and D. D. Pollard, “Testing constitutive equations for brittle-ductile deformation associated with faulting in granitic rock," Journal of Geophysical Research: Solid Earth, vol. 122, no. 8, pp. 6269-6293, 2017.

[40] P. D. Bons, T. Fusswinkel, E. Gomez-Rivas, G. Markl, T. Wagner, and B. Walter, "Fluid mixing from below in unconformity-related hydrothermal ore deposits," Geology, vol. 42, no. 12, pp. 1035-1038, 2014.

[41] M. S. Paterson and F. C. Luan, "Quartzite rheology under geological conditions," in Deformation Mechanisms, Rheology and Tectonics: Geological Society, R. J. Knipe and E. H. Rutter, Eds., vol. 54, pp. 299-307, Special Publications, London, 1990. 
[42] G. C. Gleason and J. Tullis, "A flow law for dislocation creep of quartz aggregates determined with the molten salt cell," Tectonophysics, vol. 247, no. 1-4, pp. 1-23, 1995.

[43] J. F. Nye, "The flow law of ice from measurements in glacier tunnels, laboratory experiments and the Jungfraufirn borehole experiment," Proceedings of the Royal Society of London. Series A. Mathematical and Physical Sciences, vol. 219, no. 1139, pp. 477-489, 1953.

[44] M. Dabrowski, R. Powell, and Y. Podladchikov, "Viscous relaxation of grain-scale pressure variations," Journal of Metamorphic Geology, vol. 33, no. 8, pp. 859-868, 2015.

[45] E. Huenges, J. Erzinger, J. Kück, B. Engeser, and W. Kessels, "The permeable crust: geohydraulic properties down to 9101 m depth," Journal of Geophysical Research, vol. 102, no. B8, pp. 18255-18265, 1997.

[46] H. Kern and R. Schmidt, "Physical properties of the KTB core samples at simulated in situ conditions," Scientific Drilling, vol. 1, pp. 217-223, 1990.

[47] J. R. Farver and R. A. Yund, "Oxygen diffusion in quartz: Dependence on temperature and water fugacity," Chemical Geology, vol. 90, no. 1-2, pp. 55-70, 1991.

[48] P. Y. F. Robin, "Pressure solution at grain-to-grain contacts," Geochimica et Cosmochimica Acta, vol. 42, no. 9, pp. 13831389, 1978.

[49] J. Wheeler, "The significance of grain-scale stresses in the kinetics of metamorphism," Contributions to Mineralogy and Petrology, vol. 97, no. 3, pp. 397-404, 1987.

[50] S. Staude, P. D. Bons, and G. Markl, "Hydrothermal vein formation by extension-driven dewatering of the middle crust: An example from SW Germany," Earth and Planetary Science Letters, vol. 286, no. 3-4, pp. 387-395, 2009.

[51] M. A. Etheridge, "Differential stress magnitudes during regional deformation and metamorphism: upper bound imposed by tensile fracturing," Geology, vol. 11, no. 4, pp. 231-234, 1983.

[52] P. D. Bons and B. P. van Milligen, "new experiment to model self-organized critical transport and accumulation of melt and hydrocarbons from their source rocks," Geology, vol. 29, no. 10, pp. 919-922, 2001.

[53] T. Sachau, P. D. Bons, and E. Gomez-Rivas, "Transport efficiency and dynamics of hydraulic fracture networks," Frontiers in Physics, vol. 3, 2015.

[54] P. D. Bons, "The formation of large quartz veins by rapid ascent of fluids in mobile hydrofractures," Tectonophysics, vol. 336, no. 1-4, pp. 1-17, 2001. 